\title{
Carbohydrate-Binding Agents Efficiently Prevent Dendritic Cell- Specific Intercellular Adhesion Molecule-3-Grabbing Nonintegrin (DC-SIGN)-Directed HIV-1 Transmission to T Lymphocytes
}

\author{
Jan Balzarini, Yven Van Herrewege, Kurt Vermeire, Guido Vanham, and Dominique Schols \\ Rega Institute for Medical Research, Katholieke Universiteit Leuven, Leuven, Belgium (J.B., K.V., D.S.); and Institute for \\ Tropical Medicine, Antwerp, Belgium (Y.V.H., G.V.)
}

Received August 25, 2006; accepted October 20, 2006

\begin{abstract}
Exposure of HIV-1 to dendritic cell-specific intercellular adhesion molecule-3-grabbing nonintegrin (DC-SIGN)-expressing B-lymphoblast Raji cells (Raji/DC-SIGN) but not to wild-type Raji/0 cells results in the capture of HIV- 1 particles to the cells as measured by the quantification of cell-associated p24 antigen. Cocultivation of HIV-1-captured Raji/DC-SIGN cells with uninfected $\mathrm{CD} 4^{+}$T lymphocyte $\mathrm{C} 8166$ cells results in abundant formation of syncytia within $36 \mathrm{~h}$ after cocultivation. Short preexposure of HIV-1 to carbohydrate-binding agents (CBA) dose dependently prevents the Raji/DC-SIGN cells from efficiently binding the virus particles, and no syncytia formation occurs upon subsequent cocultivation with $\mathrm{C} 8166$ cells. Thus, the mannose-specific [i.e., the plant lectins Hippeastrum hybrid agglutinin (HHA), Galanthus nivalis agglutinin (GNA), Narcissus pseudonarcissus agglutinin; and Cymbidium agglutinin (CA); the procaryotic cyanovirin-N (CV-N); and the monoclonal antibody 2G12) and $N$-acetylglucosamine-specific (i.e., the plant lectin Urtica dioica agglutinin) CBAs efficiently abrogate the
\end{abstract}

DC-SIGN-directed HIV-1 capture and subsequent transmission to $\mathrm{T}$ lymphocytes. In this assay, the CD4-down-regulating cyclotriazodisulfonamide derivative, the CXCR4 and CCR5 coreceptor antagonists 1-[[4-(1,4,8,11-tetrazacyclotetradec-1ylmethyl)phenyl]methyl] -1,4,8,11-tetrazacyclotetradecane (AMD3100) and maraviroc, the gp41-binding enfuvirtide, and the polyanionic substances dextran sulfate $\left(M_{\mathrm{r}} 5000\right)$, sulfated polyvinyl alcohol, and the naphthalene sulfonate polymer PRO-2000 were markedly less efficient or even completely ineffective. Similar observations were made in primary monocyte-derived dendritic cell cultures that were infected with HIV-1 particles that had been shortly pre-exposed to the CBAs CV-N, CA, HHA, and GNA and the polyanions DS-5000 and PRO-2000. The potential of CBAs, but not polyanions and other structural/functional classes of entry inhibitors, to impair DC-SIGN-expressing cells in their capacity of transmitting HIV to T lymphocytes might be an important property to be taken into consideration in the eventual choice to move microbicide candidate drugs to the clinical setting.
Dendritic cells (DC) function as antigen-presenting cells that capture microorganisms that enter the peripheral mu-

\footnotetext{
The research was supported by the Geconcerteerde Onderzoeksacties (GOA 05/19), the Flemish Foundation for Scientific Research (no. G-0267-04), the European Commission (René Descartes Prize-2001 HPAW-2002-90001, and EMPRO 503558 of the 6th Frame Work Programme), the Agence Nationale de Recherches sur le SIDA, and the Centers of Excellence from the Katholieke Universiteit Leuven (EF/05/15).

Article, publication date, and citation information can be found at http://molpharm.aspetjournals.org.

doi:10.1124/mol.106.030155.
}

cosal tissues. After antigen uptake, the immature DCs migrate to the $\mathrm{T}$ cell areas of secondary lymphoid organs. During this migration, DCs mature and tend to form clusters with $\mathrm{T}$ cells, initiating adaptive immune responses (Banchereau and Steinman, 1998). The $\beta 2$ integrins LFA- 1 and $\alpha \mathrm{D} \beta 2$ present at DC are believed to bind to ICAM-3, which is expressed at high levels on resting T cells. However, this is clearly not the sole interaction between $\mathrm{DC}$ and $\mathrm{T}$ cell populations. It has indeed been shown that the ICAM-3 binding C-type lectin [designated dendritic cell-specific ICAM-3 grab-

ABBREVIATIONS: DC, dendritic cell; ICAM, intercellular adhesion molecule; DC-SIGN, dendritic cell-specific ICAM-3-grabbing nonintegrin; CBA, carbohydrate-binding agent; GNA, Galanthus nivalis agglutinin; HHA, Hippeastrum hybrid agglutinin; NPA, Narcissus pseudonarcissus agglutinin; CA, Cymbidium hybrid agglutinin; UDA, Urtica dioica agglutinin; UC-781, N-[4-chloro-3-(3-methylbut-2-enoxy)phenyl]-2-methyl-furan-3-carbothioamide; CV-N, cyanovirin; PRO-2000, naphthalene sulfonate polymer; PVAS, sulfated polyvinyl alcohol; MO, monocyte-derived; mAb, monoclonal antibody; DS-5000, dextran sulfate $\left(M_{\mathrm{r}}\right.$ 5000); CADA, cyclotriazodisulfonamide; Ag, antigen. 
bing nonintegrin (DC-SIGN)], exclusively expressed by DC, mediates a strong adhesion between $\mathrm{DC}$ and resting $\mathrm{T}$ cells and would be essential for DC-induced $\mathrm{T}$ cell proliferation (Geijtenbeek et al., 2000b).

DC-SIGN is a $44-\mathrm{kDa}$ C-type $\left(\mathrm{Ca}^{2+}\right.$-dependent) lectin that binds to the mannose and fucose moieties present on the HIV gp120 envelope (Curtis et al., 1992). It does not function as a receptor for viral entry into DC; rather, it promotes efficient infection in trans of cells that express CD4 and chemokine coreceptors CXCR4/CCR5 (Geijtenbeek et al., 2000a). Given the important role of DC-SIGN-expressing DC in the initial infection by HIV, the design and development of candidate microbicide drugs have to allow for this mechanism of dissemination of the incoming virus and would preferably have the capacity to interrupt or abrogate this process.

Because HIV infection studies and cultivation of immature DCs are tedious and labor-intensive, other approaches have been introduced to study the role of DC-SIGN in HIV transmission, including Raji cells stably transfected with DCSIGN (Geijtenbeek et al., 2000a). These cells have previously been misidentified as THP-1 cells (Wu et al., 2004). It has been shown that such Raji/DC-SIGN-transfected cells bind to HIV-1 gp120 bound to beads (Geijtenbeek et al., 2000a). It was also demonstrated that such Raji/DC-SIGN cells capture and transmit HIV at efficiencies comparable with those of monocyte-derived dendritic cells (Geijtenbeek et al., 2000a; Baribaud et al., 2002; Trumpfheller et al., 2003). Therefore, we used this cell model to investigate a number of different structural and functional classes of HIV entry inhibitors for their ability to prevent DC-SIGN-directed capture of HIV. If active, such compounds should have the potential to impair the ability of monocyte-derived dendritic cells to capture HIV and to transmit HIV to T lymphocytes. The outcome of this type of studies would be very helpful to guide the choice of potential candidate microbicide drugs (Balzarini et al., 2004; Balzarini and Van Damme, 2006). We found that carbohydrate-binding agents (CBA) targetting HIV gp120, such as plant lectins, cyanovirin, and the monoclonal antibody ( $\mathrm{mAb}$ ) 2G12 but not other entry inhibitors, such as gp41- and (coreceptor-targetting drugs, or polyanionic compounds, are endowed with a dual mechanism of antiviral action: 1) preventing transmission of HIV from DC-SIGN-expressing (i.e., dendritic) cells to $\mathrm{T}$ lymphocytes, and 2) directly inhibiting $\mathrm{HIV}$ infection of $\mathrm{CD} 4^{+} \mathrm{T}$ lymphocytes by preventing virus entry.

\section{Materials and Methods}

Test Compounds. The mannose-specific plant lectins from $G a$ lanthus nivalis (GNA), Hippeastrum hybrid (HHA), Narcissus pseudonarcissus (NPA) and Cymbidium hybrid (CA) and the $N$-acetylglucosamine-specific plant lectin from Urtica dioica (UDA) were derived and purified from these plants, as described previously (Van Damme et al., 1987, 1988, 1991). UC-781 was obtained from Crompton Ltd. (Middlebury, CT). Tenofovir was from Gilead Sciences (Foster City, $\mathrm{CA})$, nevirapine was from Boehringer Ingelheim Roxane, Inc. (Columbus, OH), lamivudine was from GlaxoSmithKline (Uxbridge, Middlesex, UK), and zidovudine was from Sigma (St. Louis, MO). The CXCR4 antagonist AMD3100 was from AnorMed (Langley, BC, Canada), and dextran sulfate $\left(M_{\mathrm{r}} 5000\right)$ was from Sigma. Maraviroc was synthesized as described previously (Dorr et al., 2005). T20 (pentafuside, enfuvirtide) was kindly provided by AIDS Research Alliance (Los Angeles, CA) and cyanovirin (CV-N) by Dr. J.B. Mc-
Mahon (National Institutes of Health, Bethesda, MD) and Dr. A. Bolmstedt (Göteborg, Sweden). The monoclonal antibody 2G12 was purchased from Polymun Scientific (Vienna, Austria). The mAb F105 (Posner et al., 1991, 1993; Wilkinson et al., 2005) was kindly provided by Tibotec (Mechelen, Belgium), and the mAb 9206 (Burkly et al., 1995) was obtained from PerkinElmer Life and Analytical Sciences (Boston, MA). PRO-2000 (Scordi-Bello et al., 2005) was a kind gift from Dr. G. Vanham (Institute of Tropical Medicine, Antwerp, Belgium) and sulfated polyvinyl alcohol (PVAS) was synthesized by Dr. S. Görög (Budapest, Hungary). CADA was a kind gift of Dr. T. Bell (University of Nevada, Reno).

Cells. Human T lymphocytic C8166 cells were obtained from the American Type Culture Collection (Manassas, VA). The Raji/DCSIGN cells were constructed by Geijtenbeek et al. (2000a). Wild-type Raji/0 and DC-SIGN-expressing Raji/DC-SIGN cells were kindly provided by Dr. L. Burleigh (Institut Pasteur, Paris, France). All cell lines mentioned were cultivated in RPMI-1640 medium supplemented with $10 \%$ fetal bovine serum (Cambrex Bio Science Verviers S.p.r.l., Verviers, Belgium), $2 \mathrm{mM}$ L-glutamine, and $0.075 \mathrm{M}$ $\mathrm{NaHCO}_{3}$.

Viruses. HIV-1( $\left.\mathrm{III}_{\mathrm{B}}\right)$ was provided by Dr. R. C. Gallo and Dr. M. Popovic (Institute of Human Virology, University of Maryland, Baltimore, MD).

Antiretrovirus Assays. C8166 cells ( $5 \times 10^{5}$ cells per ml) were suspended in fresh culture medium and infected with HIV-1 at $100 \times$ the $\mathrm{CCID}_{50}$ per $\mathrm{ml}$ of cell suspension. Then, $100 \mu \mathrm{l}$ of the infected cell suspension was transferred to microplate wells, mixed with $100 \mu \mathrm{l}$ of the appropriate dilutions of the test compounds, and further incubated at $37^{\circ} \mathrm{C}$. After 3 to 4 days, giant cell formation was recorded microscopically in the $\mathrm{C} 8166$ cell cultures, and the number of giant cells was estimated as a percentage of the number of giant cells present in the nontreated virus-infected cell cultures $(\sim 50$ to 100 giant cells in one microscopic field when examined at a microscopic magnitude of $100 \times)$. The $50 \%$ effective concentration $\left(\mathrm{EC}_{50}\right)$ corresponds to the compound concentrations required to prevent syncytium formation by $50 \%$ in the virus-infected C8166 cell cultures.

Exposure of Raji Cells to HIV-1 and Subsequent Cocultivation with C8166 Cells. Exponentially growing B-lymphocyte wildtype Raji/0 and DC-SIGN-expressing Raji/DC-SIGN cells were suspended in cell culture medium at $6 \times 10^{6}$ cells $/ 400 \mu \mathrm{l}$. Then, 0.4-ml cell suspensions were exposed to $600 \mu \mathrm{l}$ of wild-type HIV-1( $\left.\mathrm{III}_{\mathrm{B}}\right)$ $\left(2.2 \times 10^{6} \mathrm{pg} / \mathrm{ml} \mathrm{p} 24\right)$ for $60 \mathrm{~min}$, after which $39 \mathrm{ml}$ of culture medium was added to the virus-infected cell culture. The cells were centrifuged at $1250 \mathrm{rpm}$ for $10 \mathrm{~min}, 39.9 \mathrm{ml}$ of supernatant was carefully removed, and the virus-exposed cells were resuspended in $40 \mathrm{ml}$ of medium. After a second centrifugation step, $39.9 \mathrm{ml}$ of supernatant was again removed, and the remaining $0.1-\mathrm{ml}$ cell suspension was 10 -fold diluted in cell culture medium to $1 \mathrm{ml}$. Under these experimental (washing) conditions, a maximum of 8 pg of HIV-1 p24 could have remained in the $1 \mathrm{ml}$-supernatant (or $0.4 \mathrm{pg}$ in $50 \mu \mathrm{l}$ ). A $50-\mu \mathrm{l}$ cell suspension was withdrawn for p24 determination by an HIV-1 p24 enzyme-linked immunosorbent assay, and $50 \mu \mathrm{l}$ of the Raji/DCSIGN cell suspension was added to 96 -well microplates in which $100-\mu \mathrm{l}$ compound dilutions were present. Then, $50 \mu \mathrm{l}$ of C8166 cells $\left(10^{7} / \mathrm{ml}\right)$ were added to each well. The cocultures were incubated at $37^{\circ} \mathrm{C}$ in a $\mathrm{CO}_{2}$-controlled humidified incubator, and microscopically scored for syncytia formation at $\sim 36$ to $48 \mathrm{~h}$ after virus-exposure/ cocultivation. It should be mentioned that the maximum amount of virus that could have remained in the culture medium $(<1 \mathrm{pg}$ of HIV-1 p24) is unable to result in HIV-1-induced giant cell formation in the C8166 cell cultures within the time period of analysis (36-48 h).

Effect of Continuous Presence of Test Compounds on Syncytia Formation in Cocultures of Virus-Exposed Raji/DCSIGN Cells and Uninfected C8166 Cells. Raji/DC-SIGN cell cultures were exposed to HIV-1 for 30 min and subsequently thoroughly washed with culture medium as described above. Then, $2 \times 10^{5}$ 
Raji/DC-SIGN cells $(50 \mu \mathrm{l})$ were seeded in 96 -well microtiter plates in the presence of serial (5-fold) dilutions of the test compounds ( 50 $\mu \mathrm{l})$. Immediately after seeding, $2 \times 10^{5} \mathrm{C} 8166$ cells $(100 \mu \mathrm{l})$ were added to each well. After 36 to $48 \mathrm{~h}$, syncytia formation was recorded microscopically, and the $50 \%$ effective concentration $\left(\mathrm{EC}_{50}\right)$ of each test compound was determined as the compound concentration required to inhibit giant cell formation by $50 \%$.

Effect of Short Exposure of HIV-1 to Test Compounds on HIV-1-Capture by Raji/DC-SIGN Cells. High amounts of HIV-1 particles $\left(100 \mu \mathrm{l} ; 2.2 \times 10^{6} \mathrm{pg} / \mathrm{ml}\right)$ were exposed to serial dilutions of the test compounds $(400 \mu \mathrm{l})$ for $30 \mathrm{~min}$. Then, the drug-exposed virus suspensions $(500 \mu \mathrm{l})$ were mixed with Raji/DC-SIGN cell suspensions $\left(500 \mu \mathrm{l} ; 10^{6}\right.$ cells) for $60 \mathrm{~min}$ at $37^{\circ} \mathrm{C}$, after which the cells were thoroughly washed twice with $40 \mathrm{ml}$ culture medium as described above. This procedure resulted in a final dilution of the initial compound concentrations by at least 160,000-fold. The Raji/DC-SIGN cell cultures were then analyzed for p24 content, $200 \mu \mathrm{l}$ mixed with $2 \times 10^{5}$ C8166 cells ( $800 \mu \mathrm{l}$ ) (resulting in a further 5 -fold dilution of the original amount of exposed test compound) and further incubated in 48 -well plates for 36 to $48 \mathrm{~h}$ at $37^{\circ} \mathrm{C}$. Then, the syncytia formation in the cell cultures was recorded microscopically.

Flow Cytometry Analysis. Cells were stained with anti-DCSIGN (DCN46-fluorescein isothiocyanate; BD Biosciences, San Jose, CA) and anti-CD4 (SK3-fluorescein isothiocyanate; BD Biosciences) and were processed for flow cytometry as described previously (Vermeire et al., 2003).

Antiviral Activity of Test Compounds in MO-DC Cocultured with T Lymphocytes. The preparation of monocyte-derived DC (MO-DC) and the method for the evaluation of the antiviral activity of test compounds has been described previously (Van Herrewege et al., 2002, 2004). In brief, HIV-1(BaL) was pre-exposed to several dilutions of the test compounds for $30 \mathrm{~min}$ before infection of primary MO-DC cultures for $2 \mathrm{~h}$ (in the presence of the test compounds). The cells were then carefully washed and cocultured with autologous CD4+ T cells for $24 \mathrm{~h}$. Then, the cell cultures were washed again and further incubated with fresh culture medium for 14 days in the absence of any compound. The $\mathrm{EC}_{50}$ value of the test compounds was defined as the compound concentration required to inhibit p24 Ag production in the MO-DC/T lymphocyte cocultures by $50 \%$.

\section{Results}

Choice of the Test Compounds. The following functionally and structurally different classes of anti-HIV drugs that are targeting virus entry have been chosen to be subject of the present study: 1) HIV gp120-interacting compounds, including the CBAs [i.e., mannose- and $N$-acetylglucosaminespecific plant lectins (HHA, GNA, NPA, CA, UDA) and the procaryotic mannose-specific CV-N]; 2) the mAbs $2 \mathrm{G} 12$ (recognizing high-mannose glycan on the silent face of gp120) (Scanlan et al., 2002), F105 (recognizing the CD4 binding site on HIV-1 gp120) (Posner et al., 1991, 1993; Wilkinson et al., 2005), and 9205 (recognizing the V3 loop in HIV-1 gp120) (Burkly et al., 1995); 3) the polyanionic molecules DS-5000, PVAS, and PRO-2000; 4) the gp41-targetting enfuvirtide; 5) the CXCR4 coreceptor antagonist AMD3100, 6) the CCR5 coreceptor antagonist maraviroc, and 7) the CD4-down-regulating CADA molecule.

Exposure of B Lymphocyte Raji/0 and Raji/DC-SIGN Cell Cultures to HIV-1( III $_{\mathbf{B}}$ ). Flow cytometry analysis revealed that the DC-SIGN-transfected Raji/DC-SIGN cells abundantly expressed DC-SIGN on their membrane, whereas the wild-type Raji/0 cells did not. In addition, CD4 and CCR5 were absent in both cell lines, whereas CXCR4 was equally present on both cell lines (Fig. 1). Wild-type Raji and stably DC-SIGN-expressing Raji cells were exposed to HIV-1 $\left(\mathrm{III}_{\mathrm{B}}\right)$ particles $\left(2.2 \times 10^{5} \mathrm{pg}\right.$ of $\left.\mathrm{p} 24\right)$ for $60 \mathrm{~min}$, after which the unadsorbed virus was carefully removed by several washing steps. It was calculated that after the serial washing steps, less than $1 \mathrm{pg}$ of HIV-1 p24 (below detection limit) remained present in the supernatant of the Raji cell cultures. Whereas no p24 Ag $(<10 \mathrm{pg}$ of p24 Ag/ml) (detection limit) associated with the Raji/0 cells could be recorded, consistent p24 Ag associated with Raji/DC-SIGN cells could be reliably measured and calculated to be 824 to $1450 \mathrm{pg}$ of p24 Ag/ml (average, $1063 \mathrm{pg}$ of p24 Ag/ml). Further incubation of the virus-exposed Raji/DC-SIGN cell cultures did not result in a productive infection because no signs of increased p24 Ag amounts in the cell cultures could be observed after 3 and 4 days of culture. In addition, no syncytia were microscopically observed to appear in the HIV-1-exposed Raji/DC-SIGN cell cultures.

Inhibitory Effect of Test Compounds on the Ability of Raji/DC-SIGN to Capture HIV-1 Particles. A broad variety of virus entry inhibitors have been included in the study (Table 1). There were striking differences in the potential of the different classes of HIV entry inhibitors to prevent capture of HIV-1 particles by Raji/DC-SIGN cells. The carbohydrate-binding agents dose-dependently inhibited capture of HIV-1 by the Raji/DC-SIGN cells. The most inhibitory CBA was CV-N, which inhibited HIV capture at an $\mathrm{IC}_{50}$ of 0.035 $\mu \mathrm{g} / \mathrm{ml}$. NPA and CA were inhibitory at 0.7 to $2.4 \mu \mathrm{g} / \mathrm{ml}$, whereas UDA, GNA, and HHA had $\mathrm{IC}_{50}$ values ranging between 8.5 and $18 \mu \mathrm{g} / \mathrm{ml}$. In addition, the $\mathrm{mAb} 2 \mathrm{G} 12$ showed profound inhibition $\left(\mathrm{IC}_{50}, 0.80 \mu \mathrm{g} / \mathrm{ml}\right.$ ) (Table 1 ). It is noteworthy that whereas the mAb F105 recognizing the CD4binding site on gp120 was not effective at al at $2 \mu \mathrm{g} / \mathrm{ml}$, the $\mathrm{mAb} 9205$ recognizing the V3 loop of gp120 was highly efficient in preventing HIV capture to Raji/DC-SIGN cells $\left(\mathrm{EC}_{50}\right.$ $\leq 0.05 \mu \mathrm{g} / \mathrm{ml}$ ). In contrast, none of the other classes of HIV entry inhibitors, including the gp41-, CXCR4-, CCR5-, and CD4-targetting drugs were inhibitory at the concentrations tested. It is noteworthy that the polyanions DS-5000, PVAS, and PRO-2000 did not inhibit HIV capture by the Raji cells. Instead, these three compounds even stimulated HIV capture by $\sim 2$-fold at the highest concentrations tested, a phenomenon not observed with any of the other entry inhibitors (Fig. 2).

Cocultivation of T Lymphocyte C8166 Cells and HIV. Exposed Raji/DC-SIGN Cells. Because we have shown that DC-SIGN-expressing Raji cell cultures can capture HIV-1 particles (as dendritic cells do), it would be important to reveal whether cocultivation of such HIV-1-exposed Raji/ DC-SIGN cells with T lymphocyte cells enable transmission of the virus particles to the T lymphocyte cells (as dendritic cells do). Indeed, we observed that in cocultures of uninfected C8166 cells and HIV-1-exposed Raji/DC-SIGN cells (from which unadsorbed virus particles were carefully removed in the Raji/DC-SIGN cell cultures before cocultivation with the C8166 cells) cell clusters appear in which the first microscopically visible syncytia [less than $\sim 10$ in one microscopic field (augmentation $100 \times$ )] became apparent already after $\sim 10$ to $12 \mathrm{~h}$. After $24 \mathrm{~h}$, the number of giant cells considerably increased in the cell clusters, and at $36 \mathrm{~h}$ after cocultivation, an abundant amount of pronounced syncytia were present ( $\sim 50$ to 100 in one microscopic field). The microscopic view of the different Raji/DC-SIGN and C8166 (co)-cultures are de- 
picted in Fig. 3, A-F. It is noteworthy that Raji/DC-SIGN cells exposed to HIV-1 for $30 \mathrm{~min}$ and carefully washed afterward could also efficiently form syncytia when C8166 cells were added to the Raji/DC-SIGN cell cultures at $24,48,72$, and $96 \mathrm{~h}$ after exposure to the virus. This means that the captured virus can stay infectious for at least $96 \mathrm{~h}$ after exposure to the Raji/DC-SIGN cells. When an HIV-1 reverse transcriptase inhibitor was added at the time of mixing the uninfected C8166 cells with the virus-exposed Raji/DC-SIGN cells (after careful removal of unadsorbed virus particles), no syncytia were observed in the cell cocultures. The lack of giant cell formation in such cocultures was observed when five different RT inhibitors, including the nucleoside reverse transcriptase inhibitors zidovudine and lamivudine, the nucleotide reverse transcriptase inhibitor tenofovir, and the non-nucleoside reverse transcriptase inhibitors nevirapine and UC781 were added at the time of cocultivation. These findings clearly indicate that the giant cell formation in the cocultures is due to transmission of the Raji/DC-SIGN-captured virus particles to the $\mathrm{C} 8166$ cells and requires active virus replication (which can be inhibited by the RT inhibitors) in the T lymphocyte cells. Such a phenomenon is also

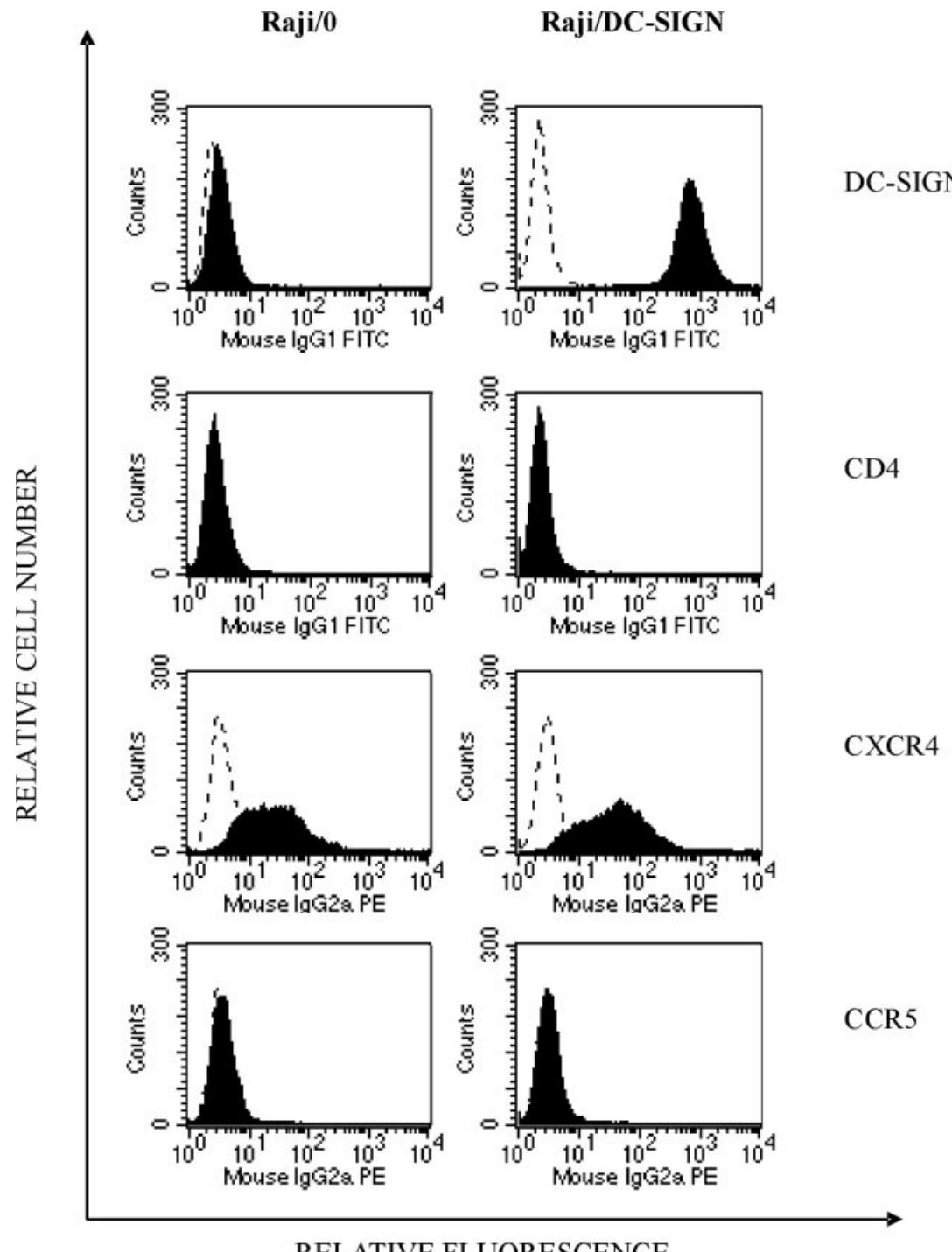

thought to occur in the in vivo situation (i.e., in a person infected with HIV).

Inhibitory Effect of Entry Inhibitors on Syncytia Formation in Cocultures of C8166 Cells and Virus-Exposed Raji/DC-SIGN Cells. In a first set of experiments, the entry inhibitors were administered to HIV-1-infected C8166 cells at the time of infection (Table 2, first column). Cyanovirin was exquisitely inhibitory $\left(\mathrm{EC}_{50}, 0.007 \mu \mathrm{g} / \mathrm{ml}\right)$ among the CBAs. In addition, NPA and CA inhibited HIVinduced giant cell formation at an $\mathrm{EC}_{50}$ of 0.85 to $0.90 \mu \mathrm{g} / \mathrm{ml}$. HHA, GNA, and UDA were less inhibitory $\left(\mathrm{EC}_{50}, 13-25\right.$ $\mu \mathrm{g} / \mathrm{ml})$. The gp41 inhibitor enfuvirtide, the CXCR4 antagonist AMD3100, and the CD4 down-regulator CADA were very inhibitory, whereas the CCR5 antagonist maraviroc was obviously devoid of antiviral activity. The polyanions DS5000, PVAS, and PRO-2000 inhibited syncytia formation at $\mathrm{EC}_{50}$ values ranging between 0.3 and $1.4 \mu \mathrm{g} / \mathrm{ml}$ (Table 1 ).

In a second set of experiments, the test compounds were added to the cocultures of uninfected C8166 cells and Raji/ DC-SIGN cells that were pre-exposed to HIV (followed by a careful removal of unadsorbed virus) and were kept present throughout the further cell culture incubation period (Table

Fig. 1. Cell surface expression of the receptors DC SIGN, CD4, CXCR4, and CCR5 on the Raji/0 (left) and Raji/DC-SIGN (right) cell line. The expression of the receptors is shown as a black histogram; an isotypic $\mathrm{mAb}$ was used as a negative control (dotted lines). As can be seen in the figure, only the Raji/DC-SIGN cell line expresses DC-SIGN. The CD4 and the CCR5 receptors are not expressed on either of the two cell lines, whereas the expression of CXCR4 on both cell lines is comparable. 
2 , second column). Most compounds had higher $\mathrm{EC}_{50}$ values for giant cell formation in these C8166 + HIV-1-exposed Raji/DC-SIGN cocultures than in HIV-1-infected C8166 cell

TABLE 1

Effect of test compounds on the ability of Raji/DC-SIGN cells to capture HIV-1 $\left(\mathrm{III}_{\mathrm{B}}\right)$ particles

$\mathrm{IC}_{50}$ is the $50 \%$ inhibitory concentration or compound concentration required to prevent HIV-1 capture (adsorption) by Raji/DC-SIGN cells as measured by HIV-1 p24 ELISA determination in the virus-exposed Raji/DC-SIGN cell cultures after prior and careful removal of unadsorbed virus.

\begin{tabular}{lc}
\hline Test Compound & $\mathrm{IC}_{50}$ \\
& $\mu g / m l$ \\
HHA & 8.5 \\
GNA & 18 \\
NPA & 0.7 \\
CA & 2.4 \\
CV-N & 0.035 \\
UDA & 10 \\
mAb 2G12 & 0.80 \\
mAb F105 & $>5.0$ \\
mAb 9205 & 0.20 \\
T-20 & $>25$ \\
AMD3100 & $>50$ \\
Maraviroc & $>1.0$ \\
CADA & $>50$ \\
DS-5000 & $>250$ \\
PVAS & $>250$ \\
PRO-2000 & $>25$ \\
\hline
\end{tabular}

cultures. In particular, CV-N showed a 50-fold decreased antiviral activity under these experimental conditions. Only CADA and PVAS kept their antiviral potential. DS-5000 and PRO-2000 were 6- and 20-fold less inhibitory than in the HIV-infected C8166 cell assays.

In a third set of experiments, the entry inhibitors were only exposed to HIV-1 for a short time (30 min), after which the drug-exposed virus was administered to the Raji/DC-SIGN cells for $60 \mathrm{~min}$. Unadsorbed virus particles and the test compounds were then carefully removed from the HIV-exposed Raji/DC-SIGN cell cultures before addition of the uninfected C8166 cells. These experimental conditions mimic most closely the natural situation of virus transmission from dendritic cells to T lymphocytes (Table 2 , third column). It is noteworthy that most CBAs, including the mAb 2G12, showed a pronounced dose-dependent inhibitory potential in this assay. The $\mathrm{EC}_{50}$ values rank between 0.04 (for $\mathrm{CV}-\mathrm{N}$ ) and $42 \mu \mathrm{g} / \mathrm{ml}$ (for GNA). Because NPA represents the most inhibitory agent among the plant lectins, a microscopic view of the NPA-pretreated HIV-1-exposed Raji/DC-SIGN + uninfected C8166 cell cocultures is depicted in Fig. 4. None of the other entry inhibitors except for the gp120 V3-recognizing $\mathrm{mAb} 9205$ showed a pronounced protection of the cell cultures at compound concentrations that were markedly higher than their concentrations required to inhibit syncytia

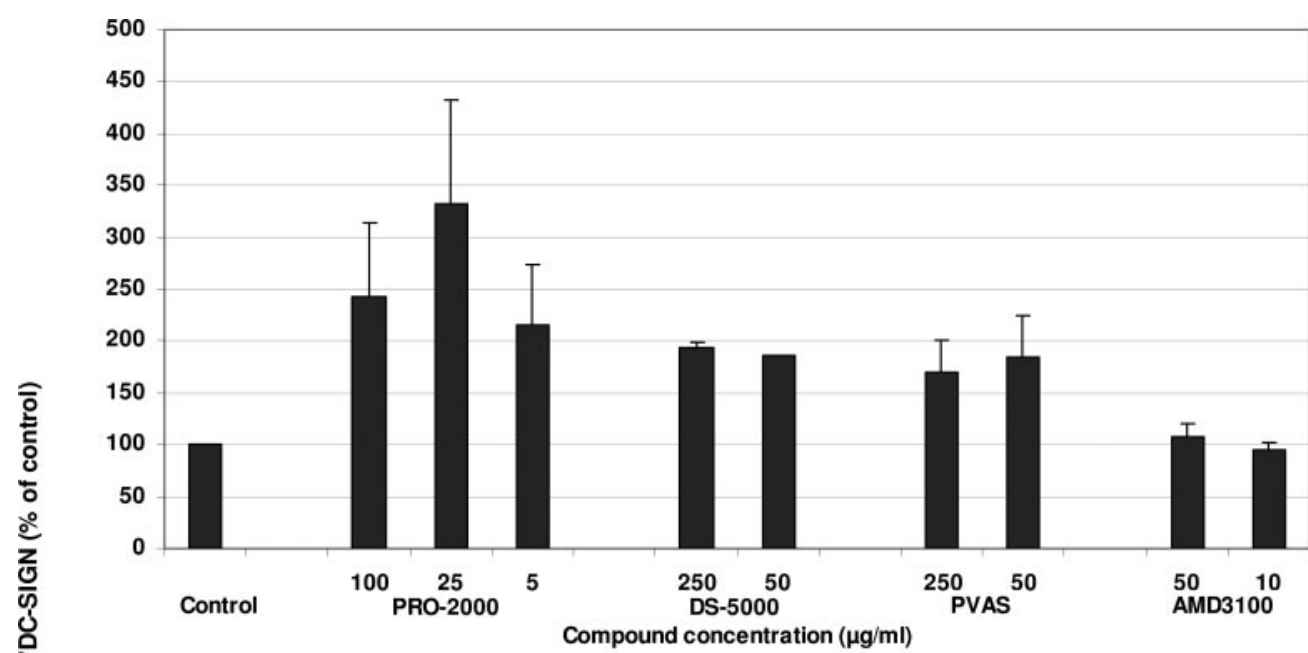

Fig. 2. Effect of test compounds on the capture of HIV-1 particles by Raji/DCSIGN cells. HIV-1( III $\left._{\mathrm{B}}\right)$ particles were exposed to various dilutions of the test compounds (30 min) before administration to Raji/DC-SIGN cells for 60 min. After removal of unbound virus by several washing (centrifugation) steps, cell-associated virus was quantified by p24 enzyme-linked immunosorbent assay. Data are the mean \pm S.D. of at least two independent experiments. The S.D. was calculated according to the formula $\sqrt{\left[\Sigma(\bar{x}-x)^{2}\right] /(n-1)}$.

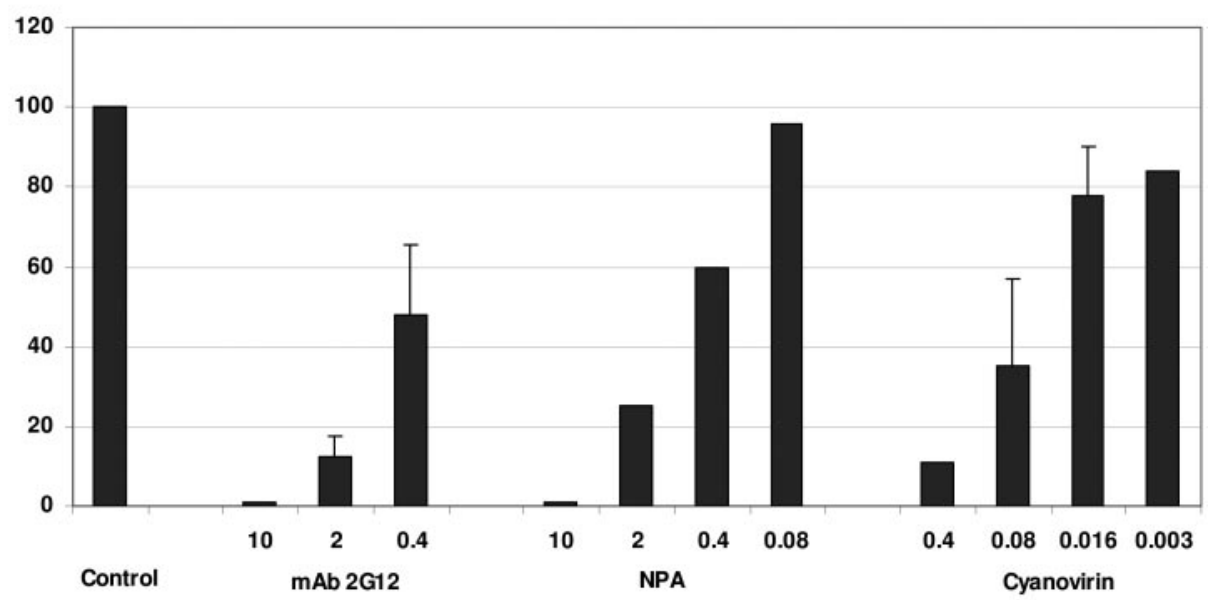

Compound concentration $(\mu \mathrm{g} / \mathrm{ml})$ 
formation in the HIV-1-infected C8166 cell cultures. The differences in the potential of the various test compounds to prevent HIV transmission became evident if the ratios of $\mathrm{EC}_{50}$ values in Table 2 were compared (i.e., third column versus first column). Indeed, whereas the CBAs were endowed with $\mathrm{EC}_{50}$ ratios that were close to 1 (0.45-5.7), all other entry inhibitors [i.e., the gp41 inhibitor and (co)-receptor antagonists, but also the polyanions] showed high ratio numbers $(>24$ to $>1428$ ) (Table 2 , fourth column).

Inhibitory Effect of CBAs and Polyanions on HIV-1 Transmission from Primary Monocyte-Derived Dendritic Cells to T Lymphocytes. To validate our findings obtained in the Raji/DC-SIGN + C8166 cocultivation model, primary MO-DCs were infected with HIV-1 parti- cles that had been preincubated (30 min) with test compound before MO-DC infection $(2 \mathrm{~h})$. Because primary monocyte-derived dendritic cells cannot be infected with the $\mathrm{X} 4$ strain $\mathrm{HIV}-1\left(\mathrm{III}_{\mathrm{B}}\right)$, the R5 HIV-1(BaL) strain was used. After careful removal of unadsorbed virus from the infected cell cultures, resting autologous CD4 T cells were added to the dendritic cells together with compound (for $24 \mathrm{~h}$ ). Then, the cultures were washed to remove the test compounds, and further incubated for 14 days in fresh culture medium in the absence of the test compounds. It is noteworthy that among the CBAs, CV-N showed an $\mathrm{EC}_{50}$ of $0.37 \mu \mathrm{g} / \mathrm{ml}$ and CA, GNA, and HHA had $\mathrm{EC}_{50}$ values of 4.2 , 3.7 , and $4.6 \mu \mathrm{g} / \mathrm{ml}$, respectively. As observed also in the Raji/DC-SIGN + C8166 cocultures, the polyanions PRO-
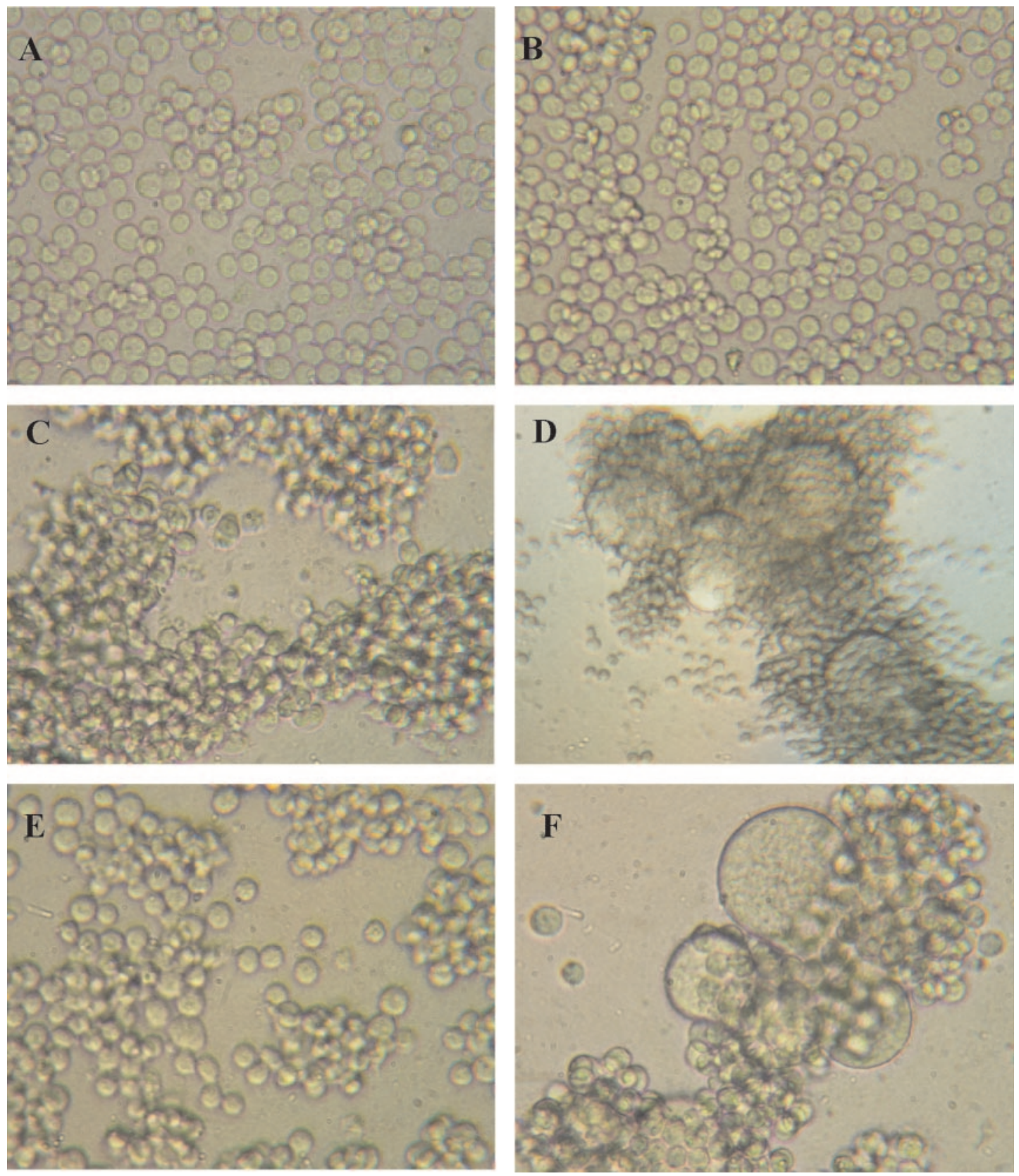

Fig. 3. Microscopic view of the following cell cultures. A, Raji/DC-SIGN cells. B, HIV-1-exposed Raji/DC-SIGN cells. C, C8166 cells. D, HIV-1-infected C8166 cells [3 days after infection with $100 \times$ the CCID $_{50}$ HIV-1 $\left(\mathrm{III}_{\mathrm{B}}\right)$ ]. E, cocultures of uninfected C8166 cells + Raji/DC-SIGN cells. F, cocultures of uninfected C8166 cells + HIV-1-exposed Raji/DC-SIGN cells (the unadsorbed virus to the Raji/DC-SIGN cells was carefully removed after a 30-min incubation time before cocultivation of the Raji/DC-SIGN cells with the uninfected C8166 cells). 
2000 and DS-5000 showed little, if any, inhibitory activity $\left(\mathrm{EC}_{50}, 32\right.$ and $>100 \mu \mathrm{g} / \mathrm{ml}$, respectively).

\section{Discussion}

The Raji/DC-SIGN cells that can capture and transmit HIV-1 particles to T lymphocytes are thought to be a reliable and relevant model system to mimic the HIV capture and transmission to T lymphocytes by primary MO-DCs (Geijtenbeek et al., 2000; Baribaud et al., 2002; Trumpfheller et al., 2003). Under our experimental conditions, Raji/DC-SIGN but not wild-type Raji/0 cells could indeed specifically capture HIV-1 particles. These HIV-1 particles could not productively infect the Raji/DC-SIGN cells. Instead, they could be efficiently transmitted to uninfected C8166 T lymphocytes [but also CEM, MT-4, and Sup T1 cells, although at a much lesser efficacy (data not shown)]. It is noteworthy that concomitant administration of RT inhibitors to the C8166 + HIV-1-exposed Raji/DC-SIGN cocultures could efficiently block the giant cell formation, pointing to an active virus replication in the C8166 cells that proved obligatory to afford the appearance of giant cells. In addition, HIV-1 particles that were captured by the Raji/DC-SIGN cells for at least $72 \mathrm{~h}$ before addition of C8166 cells were shown to be still fully infectious. Thus, this cocultivation cell model might be very useful and highly relevant for studying the effect of drugs on HIV transmission from DC-SIGN expressing (i.e., dendritic) cells to $\mathrm{T}$ lymphocytes.

Among all different types of entry inhibitors, acting against HIV gp120 and gp41, or against the (co)receptors CD4, CXCR4, and CCR5, only the carbohydrate-binding agents [such as the procaryotic cyanovirin, the plant-derived $\mathrm{CA}$ and NPA, or the mAb $2 \mathrm{G} 12$ that binds to a glycanscontaining epitope on gp120 (Scanlan et al., 2002)] were able to efficiently prevent virus transmission from virus-captured Raji/DC-SIGN cells to uninfected C8166 cells. In contrast, none of the other entry inhibitors directed against other targets in the entry process, including the polyanions, proved effective in interrupting the HIV transmission process. It was striking that the polyanions reliably stimulated HIV-1 capture by Raji/DC-SIGN cells (Fig. 2), an observation that cannot be properly explained.

We believe that our findings have high relevance to be taken into account for the choice and development of (novel) candidate microbicide drugs. Indeed, during sexual intercourse, the very first sites of interaction of HIV in the infected individual are predominantly immature DCs that are present in the vaginal mucosa. Such DCs are thought to capture cell-free virus particles through the C-type mannosespecific lectin DC-SIGN, which is abundantly present on the membrane of these dendritic cells. If, however, CBAs are present in the environment of the incoming virus, the gp120 of HIV will interact and bind with the CBAs, making it difficult for the DCs to capture the virus through its envelope gp120. Thus, based on our observations, CBAs, in particular tight-binding CBAs such as CV-N and 2G12 but also several plant-derived CBAs such as CA and NPA, would be expected to efficiently prevent capture of HIV particles by DC-SIGNexpressing DCs. This phenomenon was indeed also observed in our studies using an experimental model in which primary monocyte-derived DCs were exposed to HIV-1(BaL) that was pre-exposed with the test compounds, after which T lymphocytes were added to the DC cultures. In addition, Turville et al. (2005) have demonstrated that CV-N and plant lectins efficiently inhibited infection transfer of HIV-1(BaL) to CD4+ lymphocytes in trans by immature MO-DCs. These data validate the relevance of the HIV-exposed Raji/DCSIGN + C8166 coculture model. We were surprised to find that none of the other classes of entry inhibitors [including the polyanions, one of which, PRO-2000, is currently the subject of clinical microbicide trials (Scordi-Bello et al., 2005)] was able to efficiently interact with the HIV captive/ transmission process. This is in sharp contrast with the potent inhibitory activity of polyanions in general, and DS-5000

\section{TABLE 2}

Inhibitory activity of test compounds against HIV-1-infected C8166 cultures or HIV-1-exposed Raji/DC-SIGN cells cocultivated with uninfected C8166 cells

Data are presented as the mean \pm S.D. of two to three independent experiments. The following formula was used for the calculation of the S.D.: $\sqrt{\left[\Sigma(\bar{x}-x)^{2}\right] /(n-1)}$.

\begin{tabular}{|c|c|c|c|c|}
\hline \multirow{2}{*}{ Test Compound } & \multicolumn{3}{|c|}{$\mathrm{EC}_{50}$} & \multirow{2}{*}{ Ratio $\mathrm{EC}_{50}$ Condition $\mathrm{C} / \mathrm{A}$} \\
\hline & Condition $\mathrm{A}^{\mathrm{a}}$ & Condition $\mathrm{B}^{b}$ & Condition $\mathrm{C}^{c}$ & \\
\hline \multicolumn{5}{|c|}{$\mu g / m l$} \\
\hline HHA & $13 \pm 6.5$ & $>20$ & $32 \pm 7.5$ & 2.4 \\
\hline GNA & $20 \pm 0.0$ & $>20$ & $42 \pm 2.5$ & 2.1 \\
\hline NPA & $0.90 \pm 0.1$ & $3.1 \pm 0.9$ & $0.9 \pm 0.3$ & 1.0 \\
\hline $\mathrm{CA}$ & $0.85 \pm 0.05$ & $7.0 \pm 3.0$ & $1.5 \pm 0.5$ & 1.7 \\
\hline CV-N & $0.007 \pm 0.003$ & $0.35 \pm 0.15$ & $0.04 \pm 0.0$ & 5.7 \\
\hline UDA & $25 \pm 15$ & $45 \pm 5.0$ & $30 \pm 10$ & 1.2 \\
\hline $\mathrm{mAb} 2 \mathrm{G} 12$ & $2.0 \pm 0.0$ & $22 \pm 2.5$ & $0.9 \pm 0.1$ & 0.45 \\
\hline mAb F105 & $1.1 \pm 0.1$ & $\gg 1$ & $5 \pm 0.0$ & 4.5 \\
\hline mAb 9205 & $0.01 \pm 0.0$ & $0.045 \pm 0.005$ & $0.005 \pm 0.001$ & 0.60 \\
\hline Enfuvirtide & $0.75 \pm 0.05$ & $2.7 \pm 1.2$ & $>25$ & $>33$ \\
\hline AMD3100 & $0.035 \pm 0.015$ & $0.85 \pm 0.65$ & $>50$ & $>1428$ \\
\hline Maraviroc & $>1.0$ & $>1.0$ & $>1$ & \\
\hline CADA & $2.1 \pm 0.1$ & $1.1 \pm 0.35$ & $>50$ & $>24$ \\
\hline DS-5000 & $0.8 \pm 0.0$ & $4.8 \pm 3.2$ & $>250$ & $>312$ \\
\hline PVAS & $1.4 \pm 0.6$ & $2.2 \pm 0.25$ & $\geq 250$ & $\geq 178$ \\
\hline PRO-2000 & $0.3 \pm 0.1$ & $6.0 \pm 4.0$ & $\geq 25$ & $\geq 83$ \\
\hline
\end{tabular}

${ }^{a} 50 \%$ effective concentration required to prevent syncytia formation in HIV-1( $\left.\mathrm{III}_{\mathrm{B}}\right)$-infected C8166 cell cultures at day 3 after infection.

${ }^{b} 50 \%$ effective concentration required to prevent syncytia formation in HIV-1(III $\mathrm{B}_{\mathrm{B}}$ )-exposed Raji/DC-SIGN cell cultures that were cocultivated with uninfected C8166 cells in the continuing presence of different concentrations of the test compounds.

${ }^{c} 50 \%$ effective concentration required to prevent syncytia formation in test compound-pre-exposed HIV-1(III $\left.{ }_{B}\right)$-infected Raji/DC-SIGN cell cultures, cocultivated with uninfected C8166 cells in the absence of the test compounds. 
and PRO-2000 in particular, against infection of laboratory adapted (X4 and R5) HIV-1 strains in CD4 ${ }^{+}$T lymphocytes and macrophages (Baba et al., 1990a,b; Scordi-Bello et al., 2005) Instead, the polyanions seemed to potentiate the binding of HIV-1 to the DC-SIGN-expressing cells, a property that one would not like in a potential microbicide candidate drug. The molecular mechanism behind this observation and the physiological relevance of this phenomenon are currently unclear.

Among the mAbs, the glycan-recognizing 2G12 could efficiently prevent HIV-1 capture by Raji/DC-SIGN cells. In contrast, the mAb F105 that recognizes the CD4-binding site on gp120 was unable to efficiently prevent HIV-1 capture by Raji/DC-SIGN cells at a concentration as high as $5 \mu \mathrm{g} / \mathrm{ml}$. The mAb 9205 partially $(\sim 30-60 \%)$ blocked HIV-1 capture at concentrations that ranked between 0.01 and $0.25 \mu \mathrm{g} / \mathrm{ml}$. This means that mAb 9205 is at least 20-fold less efficient in preventing DC-SIGN-directed HIV transmission than inhibiting HIV entry in T lymphocytes. These data also indicate that not all mAbs directed against gp120 may have the potential to prevent efficiently HIV-1 transmission from DCSIGN-expressing (i.e., dendritic) cells to T lymphocytes. In fact, no glycans on gp120 are known to be involved in the primary interaction of CD4 with HIV-1 gp120. This may explain the virtual inactivity of a mAb such as F105 that specifically interacts with the CD4-binding site on gp120. It is, however, known that the gp120 V3 loop is of critical importance for efficient interaction of HIV with its coreceptor (Ghaffari et al., 2005; Clevestig et al., 2006; Pastore et al., 2006). Therefore, the mAb 9205 that binds to the V3 region of gp120 may sterically hinder the interaction of HIV-1 gp120 with the coreceptor (either CXCR4 or CCR5) and therefore efficiently prevent entry of HIV-1 into the C8166 cells but only partially prevent HIV-1 capture. Thus, mAbs should be carefully evaluated in HIV-1 transmission models, such as the Raji/DC-SIGN + C8166 coculture assay, if envisioned for potential microbicide use.

In conclusion, we have established an in vitro assay mak-
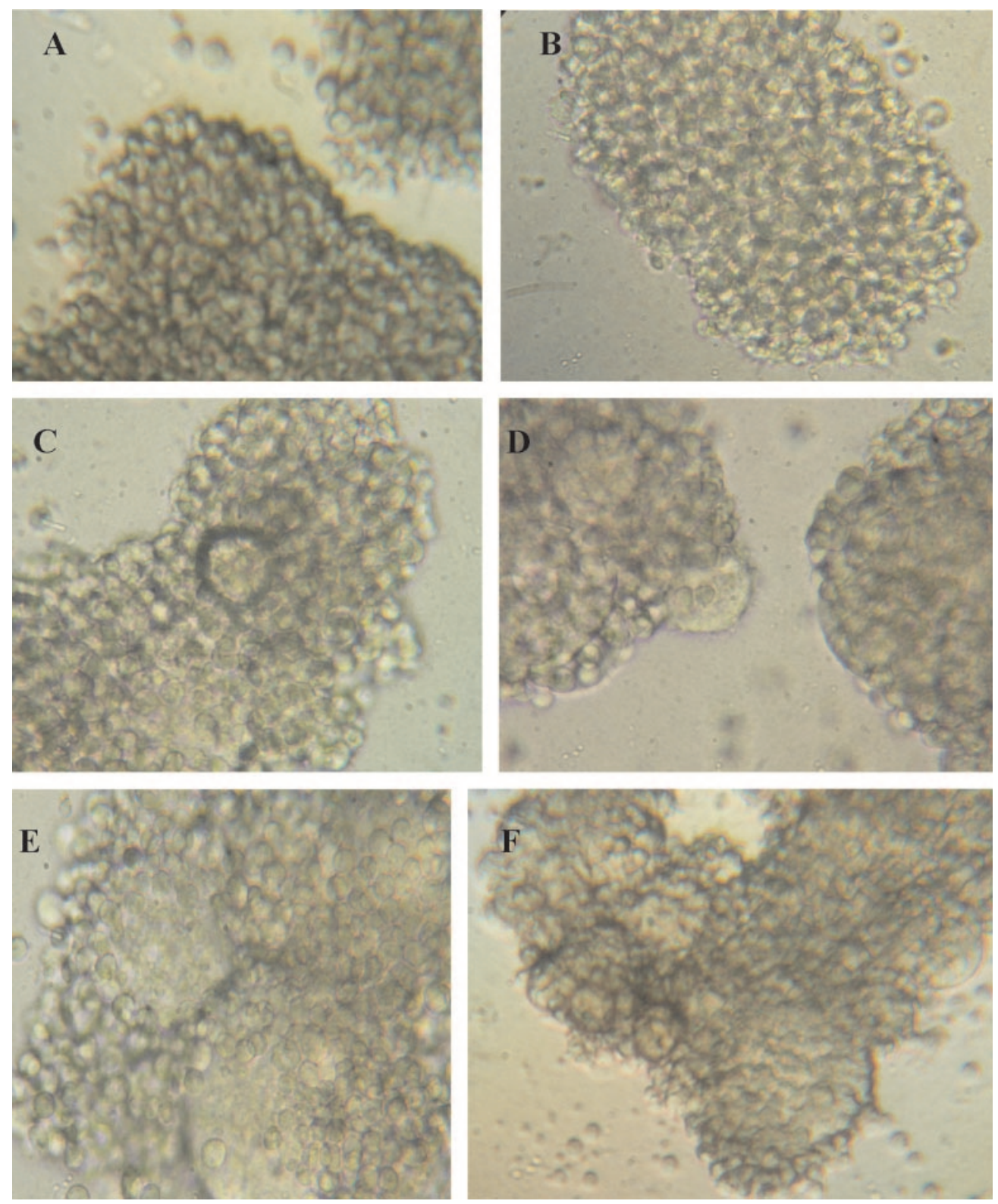

Fig. 4. Cocultures of HIV-1-exposed human B-lymphocyte Raji/DC-SIGN cells and human T lymphocyte C8166 cells in the presence of varying concentrations of the mannose-specific plant lectin NPA. A, $50 \mu \mathrm{g} / \mathrm{ml} ; \mathrm{B}, 10$ $\mu \mathrm{g} / \mathrm{ml} ; \mathrm{C}, 2 \mu \mathrm{g} / \mathrm{ml} ; \mathrm{D}, 0.4 \mu \mathrm{g} / \mathrm{ml} ; \mathrm{E}$, $0.08 \mu \mathrm{g} / \mathrm{ml} ; \mathrm{F}, 0 \mu \mathrm{g} / \mathrm{ml}$ (control). Microscopic views were taken $48 \mathrm{~h}$ after initiation of the cocultivations. 
ing use of DC-SIGN-expressing (Raji) cell cultures that can selectively capture HIV-1 particles. The cells can efficiently transmit these virus particles to T lymphocyte (C8166) cells, resulting in a productive infection and subsequent syncytia formation. We found in this model that CBAs, but not other types of HIV entry inhibitors, can efficiently interrupt and prevent HIV particle capture by the DC-SIGN-expressing cells. Although a variety of different (viral and nonviral) properties are important and need to be taken into account (Balzarini and Van Damme, 2006), the potential to interrupt the HIV transmission pathway by such drugs in the described assay model should not be neglected when making a choice on potential candidate microbicide drugs.

\section{Acknowledgments}

We are grateful to Ann Absillis, Sandra Claes, Rebecca Provinciael, and Eric Fonteyn for excellent technical assistance and Christiane Callebaut for dedicated editorial assistance.s

\section{References}

Baba M, Schols D, De Clercq E, Pauwels R, Nagy M, Gvorgyi-Edelenyi J, Low M, and Gorog S (1990a) Novel sulfated polymers as highly potent and selective inhibitors of human immunodeficiency virus replication and giant cell formation. Antimicrob Agents Chemother 34:134-138

Baba M, Schols D, Pauwels R, Nakashima H, and De Clercq E (1990b) Sulfated polysaccharides as potent inhibitors of HIV-induced syncytium formation: a new strategy towards AIDS chemotherapy. J Acquir Immune Defic Syndr 3:493-499.

Balzarini J, Hatse S, Vermeire K, Princen K, Aquaro S, Perno C-F, De Clercq E, Egberink H, Vanden Mooter G, Peumans W, et al. (2004) Mannose-specific plant lectins from the Amaryllidaceae family qualify as efficient microbicides for prevention of human immunodeficiency virus infection. Antimicrob Agents Chemother 48:3858-3870

Balzarini J and Van Damme L (2006) Anti-human immunodeficiency virus (HIV) microbicide drug candidates to prevent HIV infection. The Lancet, in press.

Banchereau J and Steinman RM (1998) Dendritic cells and the control of immunity. Nature (Lond) 392:245-252.

Baribaud E, Pohlmann S, Leslie G, Mortari F, and Doms RW (2002) Quantitative expression and virus transmission analysis of DC-SIGN on monocyte-derived dendritic cells. J Virol 76:9135-9142.

Burkly L, Mulrey N, Blumenthal R, and Dimitrov DS (1995) Synergistic inhibition of human immunodeficiency virus type 1 envelope glycoprotien-mediated cell fusion and infection by an antibody to CD4 domain 2 in combination with anti-gp120 antibodies. $J$ Virol 69:4267-4273.

Clevestig P, Pramanik L, Leitner T, and Ehrnst A (2006) CCR5 use by human immunodeficiency virus type 1 is associated closely with the gp120 V3 loop Nlinked glycosylation site. J Gen Virol 87:607-612.

Curtis BM, Scharnowske S, and Watson AJ (1992) Sequence and expression of a membrane-associated C-type lectin that exhibits CD4-independent binding of human immunodeficiency virus envelope glycoprotein gp120. Proc Natl Acad Sci USA 89:8356-8360.

Dorr P, Westby M, Dobbs S, Griffin P, Irvine B, Macartney M, Mori J, Rickett G, Smith-Burchnell C, Napier C, et al. (2005) Maraviroc (UK-427,857), a potent, orally bioavailable, and selective small-molecule inhibitor of chemokine receptor CCR5 with broad-spectrum anti-human immunodeficiency virus type 1 activity. Antimicrob Agents Chemother 49:4721-4732.

Geijtenbeek TBH, Kwon DS, Torensma R, van Vliet SJ, van Duijnhoven GCF Middel J, Cornelissen ILMHA, Nottet HSLM, KewalRamani VN, Littman DR, et al. (2000a) DC-SIGN, a dendritic cell-specific HIV-1-binding protein that enhances trans-infection of T cells. Cell 100:587-597.

Geijtenbeek TBH, Torensma R, van Vliet SJ, van Duijnhoven GCF, Adema GJ, van Kooyk Y, and Figdor CG (2000b) Identification of DC-SIGN, a novel dendritic cell-specific ICAM-3 receptor that supports primary immune responses. Cell 100: $575-585$.

Ghaffari G, Tuttle DL, Briggs D, Burkhart BR, Bhatt D, Andiman WA, Sleasman JW, and Goodenow MM (2005) Complex determinants in human immunodeficiency virus type 1 envelope gp120 mediate CXCR4-dependent infection of mac rophages. J Virol 79:13250-13261.

Pastore C, Nedellec R, Ramos A, Pontow S, Ratner L, and Mosier DE (2006) Human immunodeficiency virus type 1 coreceptor switching: V1/V2 gain-of-fitness mutations compensate for V3 loss-of-fitness mutations. J Virol 80:750-758.

Posner MR, Cavacini LA, Emes CL, Power J, and Byrn R (1993) Neutralization of HIV-1 by F105, a human monoclonal antibody to the CD4 binding site of gp120. $J$ Acquir Immune Defic Syndr 6:7-14.

Posner MR, Hideshima T, Cannon T, Mukherjee M, Mayer KH, and Byrn RA (1991) An IgG human monoclonal antibody that reacts with HIV-1/gp120, inhibits virus binding to cells, and neutralizes infection. J Immunol 146:4325-4332.

Scanlan CN, Pantophlet R, Wormald MR, Ollmann Saphire E, Stanfield R, Wilson IA, Katinger H, Dwek RA, Rudd PM, and Burton DR (2002) The broadly neutralizing anti-human immunodeficiency virus type 1 antibody $2 \mathrm{G} 12$ recognizes a cluster of $\alpha 1 \rightarrow 2$ mannose residues on the outer face of gp120. $J$ Virol 76:73067321.

Scordi-Bello IA, Mosoian A, He C, Chen Y, Cheng Y, Jarvis GA, Keller MJ, Hogarty K, Waller DP, Profy AT, et al. (2005) Candidate sulfonated and sulfated topical microbicides: comparison of anti-human immunodeficiency virus activities and mechanisms of action. Antimicrob Agents Chemother 49:3607-3615.

Trumpfheller C, Park CG, Finke J, Steinman RM, and Granelli-Piperno A (2003) Cell type-dependent retention and transmission of HIV-1 by DC-SIGN. Int Immu nol 15:289-298.

Turville SG, Vermeire K, Balzarini J, and Schols D (2005) Sugar-binding proteins potently inhibit dendritic cell human immunodeficiency virus type 1 (HIV-1) infection and dendritic-cell-directed HIV-1 transfer. $J$ Virol 79:13519-13527.

Van Damme EJM, Allen AK, and Peumans WJ (1987) Leaves of the orchid twayblade (Listera ovata) contain a mannose-specific lectin. Plant Physiol 85:566-569.

Van Damme EJM, Allen AK, and Peumans WJ (1988) Related mannose-specific lectins from different species of the family Amaryllidaceae. Physiol Plant 73:52 57

Van Damme EJM, Peumans WJ, Pusztai A, and Bardocz S (1988) Handbook of Plant Lectins: Properties and Biomedical Applications, John Wiley \& Sons, New York.

Van Herrewege Y, Michiels J, Fransen K, Van Roey J, Fransen K, Kestens L, Balzarini J, Lewi P, and Vanham G (2004) In vitro evaluation of the nonnucleoside reverse transcriptase inhibitors UC-781 and dapivirine as HIV microbicides. Antimicrob Agents Chemother 48:337-339.

Van Herrewege Y, Penne L, Vereecken C, Fransen K, van der Groen G, Kestens L, Balzarini J, and Vanham G (2002) Using reverse-transcriptase inhibitors for post-exposure prophylaxis of sexual HIV tranmission: in vitro modeling with monocyte-derived dendritic cells. AIDS Res Hum Retrovirol 18:1091-1102.

Vermeire K, Bell TW, Choi H-J, Jin Q, Samala MF, Sodoma A, De Clercq E, and Schols D (2003) The anti-HIV potency of cyclotriazadisulfonamide analogs is directly correlated with their ability to down-modulate the CD4 receptor. Mol Pharmacol 63:203-210.

Wilkinson RA, Piscitelli C, Teintze M, Cavacini LA, Posner MR, and Lawrence CM (2005) Structure of the Fab fragment of F105, a broadly reactive anti-human immunodeficiency virus (HIV) antibody that recognizes the CD4 binding site of HIV type 1 gp120. J Virol 79:13060-13069.

Wu L, Martin TD, Carrington M, and KewalRamani VN (2004) Raji B cells, misidentified as THP-1 cells, stimulate DC-SIGN-mediated HIV transmission. Virology 318:17-23.

Address correspondence to: Prof. Dr. Jan Balzarini, Rega Institute for Medical Research, K.U. Leuven, Minderbroedersstraat 10, B-3000 Leuven, Belgium. E-mail: jan.balzarini@rega.kuleuven.be 